\title{
Vida cotidiana y experiencias morales de un grupo de jóvenes en conflicto con la ley en Santiago, Chile
}

Everyday Life and Moral Experiences of a Group of Young People in Conflict with the Law in Santiago, Chile

Vie quotidienne et expériences morales d'un groupe de jeunes en conflit avec la loi à Santiago, Chili

Mauricio Carreño Hernández, Gabriel Abarca-Brown y Esteban Radiszcz

\section{OpenEdition}

\section{Journals}

Edición electrónica

URL: https://journals.openedition.org/rccs/12420

DOI: $10.4000 /$ rccs. 12420

ISSN: 2182-7435

Editor

Centro de Estudos Sociais da Universidade de Coimbra

Edición impresa

Fecha de publicación: 1 diciembre 2021

Paginación: 69-90

ISSN: 0254-1106

Referencia electrónica

Mauricio Carreño Hernández, Gabriel Abarca-Brown y Esteban Radiszcz, «Vida cotidiana y experiencias morales de un grupo de jóvenes en conflicto con la ley en Santiago, Chile», Revista Crítica de Ciências Sociais [En línea], 126 | 2021, Publicado el 27 enero 2022, consultado el 29 enero 2022 URL: http://journals.openedition.org/rccs/12420 ; DOI: https://doi.org/10.4000/rccs. 12420 


\section{MAURICIO CARREÑO HERNÁNDEZ, GABRIEL ABARCA-BROWN, ESTEBAN RADISZCZ}

\section{Vida cotidiana y experiencias morales de un grupo de jóvenes en conflicto con la ley en Santiago, Chile}

En este artículo exploramos la vida cotidiana de un grupo de jóvenes en conflicto con la ley y las relaciones que mantienen con los dispositivos y las estrategias de la actual Ley 20.084 de Responsabilidad Penal Adolescente (LRPA). Para ello describimos el contexto etnográfico de la investigación. Posteriormente mostramos los modos de sociabilidad juvenil, sus experiencias morales y las interacciones que mantienen con los dispositivos de la LRPA. Los materiales sugieren que la experiencia juvenil se vincula a valores, códigos, normas y expectativas locales articuladas a representaciones sobre lo masculino y lo adulto. Así, a través de sus experiencias morales, los jóvenes revelan los modos en que se involucran en prácticas delictivas, así como también las fricciones y los conflictos que mantienen con los dispositivos y las estrategias de la LRPA.

Palabras clave: Chile; delincuencia juvenil; responsabilidad penal; vida cotidiana.

Palavras-chave: Chile; delinquência juvenil; responsabilidade penal; vida quotidiana.

\section{Introducción}

En el presente artículo exploramos la vida cotidiana de un grupo de jóvenes en conflicto con la ley, así como las relaciones que estos mantienen con los dispositivos y estrategias dispuestas por la actual Ley 20.084 de Responsabilidad Penal Adolescente (LRPA), con el objetivo de comprender la dimensión moral que cobra forma en la vida cotidiana de la juventud infractora. Actualmente, la LRPA es la normativa penal que se aplica

\footnotetext{
${ }^{1}$ Este artículo es un producto conjunto entre la investigación titulada "Excesos de ley. Aproximaciones a la experiencia moral de un grupo de jóvenes en conflicto con la ley" (Carreño Hernández, 2016), desarrollada por el primer autor de este trabajo en el programa de Magíster en Psicología Clínica de Adultos de la Universidad de Chile y el trabajo realizado dentro del equipo de investigación en Salud Mental y Corporalidad del Laboratorio Transdisciplinar en Prácticas Sociales y Subjetividad (LaPSoS) de la Universidad de Chile.
} 
a los/las jóvenes entre 14 y 18 años que cometen delitos. Esta ley establece un sistema penal especializado para los/las adolescentes dentro del marco de la Convención sobre los Derechos del Niño y otras normativas internacionales en la materia.

Para evitar la reducción de la dimensión moral a una estructura de categorías y principios racionales y universales (Das, 2012; Lambek, 2010), utilizaremos dos claves conceptuales. En primer lugar, la noción de experiencia moral, entendida como aquellos procesos (colectivos, interpersonales y subjetivos) locales que emergen de las condiciones y exigencias de la vida social, capaces de performar valores en lo cotidiano (Kleinman, 1999, 2006); $\mathrm{y}$, en segundo lugar, el concepto de economía moral, que enfatiza en "la producción, el reparto, la circulación y la utilización de las emociones y los valores, las normas y las obligaciones en un espacio social" (Fassin, 2018: 196).

La dimensión moral asociada a la denominada delincuencia juvenil ha cobrado especial relevancia en la actualidad a partir de los saberes expertos en la materia, que han depositado su interés en investigar los modos en virtud de los cuales los/las jóvenes infractores/as se relacionan y, por cierto, transgreden las normas sociales. En efecto, desde comienzo de la década de 1990, la alta connotación pública que han adquirido en Chile los delitos juveniles ha traído consigo el surgimiento de un espacio discursivo acerca de la delincuencia juvenil (Tsukame, 2017) donde convergen diversas explicaciones del fenómeno, estrategias para su control y representaciones sobre el/la "adolescente infractor". Sin embargo, los discursos provenientes de las disciplinas "psi" y "neuro" respecto a la criminalidad juvenil (Rose, 2012; Rose y Abi-Rached, 2013; Vidal y Ortega, 2017) han tendido a reducir esta problemática a una dimensión psicológica y neurobiológica (Radiszcz et al., 2019), mediante la consideración de los/las jóvenes como sujetos en desarrollo, es decir, en un incompleto proceso de maduración psicológica, neurológica y, ciertamente, moral (véase, por ejemplo, Iselin et al., 2009; Pardini y Loeber, 2008).

Las actuales políticas y estrategias gubernamentales en delincuencia juvenil no sólo han enfatizado en el aún incompleto desarrollo de determinadas competencias psicológicas y cognitivas en los/las jóvenes infractores/as. Por el contrario, las últimas dos décadas se han caracterizado por el afianzamiento de saberes biomédicos y psiquiátricos en torno a la criminalidad juvenil (Béhague, 2009). De hecho, diversos estudios a nivel nacional han revelado una mayor prevalencia de patologías psiquiátricas en esta población (Fundación Tierra Esperanza, 2012; Gaete et al., 2014; MINSAL, 2007; Rioseco et al., 2009), las cuales han adquirido tanto un valor explicativo como predictivo de la comisión y el mantenimiento de las conductas infractoras juveniles. 
A partir de esto, indagamos en las dimensiones sociales, culturales y políticas que articulan la experiencia moral de los/las jóvenes en conflicto con la ley en el Chile postdictatorial. Ello, a fin de tomar distancia de los discursos psicológicos y neurobiológicos en la materia, los cuales no solo han tendido a una patologización de la experiencia juvenil infractora, sino también a su naturalización como una condición característica -e incluso intrínseca- de la juventud (Radiszcz et al., 2019). Más aún, al enfatizar los componentes morales locales que articulan el problema de la delincuencia juvenil buscamos abordar el fenómeno mediante una consideración de los modos particulares a partir de los cuales los/las jóvenes en conflicto con la ley habitan cotidianamente el mundo, desarticulando aquellos discursos que desacreditan la experiencia juvenil y su dimensión moral mediante su reducción a una lógica de lo ilícito (Béhague, 2009; García, 2014).

En un primer momento, describiremos la aproximación etnográfica de esta investigación. Luego, expondremos algunos aspectos de la vida cotidiana juvenil, su escenario específico -la calle- y los conflictos y contradicciones morales que los jóvenes viven en dicho contexto. En un tercer momento, mostraremos las diversas interacciones entre los jóvenes y los dispositivos y estrategias de la LRPA. Por último, abordaremos las formas que asume la experiencia moral juvenil: sus lógicas de intercambio, sus formas de sociabilidad y la circulación de normas, obligaciones y valores. Los materiales de esta investigación sugieren que la experiencia moral de los jóvenes, a saber, los marcos normativos, las interacciones, los dilemas y los conflictos en los cuales cotidianamente participan se encuentran atravesados por discursos relativos al género, la clase y lo generacional, configurando un ethos moral a nivel local en conflicto y negociación con las representaciones y los discursos hegemónicos. Por consiguiente, la dimensión moral resulta ser un aspecto central a la hora de comprender los modos en que los jóvenes se involucran en prácticas delictivas y las fricciones que mantienen con los dispositivos y estrategias dispuestas por el sistema penal adolescente.

\section{Metodología}

\subsection{Contexto de la investigación}

La investigación contempló una aproximación etnográfica focalizada (Knoblauch, 2005) mediante la realización de observación participante con un grupo de jóvenes infractores de ley pertenecientes a una comuna [municipio] periférica de Santiago de Chile. Durante el periodo 2015-2016, la comuna donde se realizó esta investigación presentó un índice de pobreza superior al porcentaje registrado a nivel metropolitano y nacional (BCN, s.f.). El ingreso al territorio se llevó a cabo mediante el contacto con 
un dispositivo psicosocial dirigido a jóvenes con una alta participación en contextos de calle. Si bien, este dispositivo no formaba parte de la red de instituciones que administran las sanciones penales en el marco de la LRPA, un porcentaje importante de los/las jóvenes que participaban en el mismo se encontraban sujetos a sanciones penales y programas de reinserción social. La elección de dicha institución respondió al enfoque territorial de sus intervenciones y a su exterioridad respecto al sistema de justicia penal. Con esta decisión se intentó disminuir las posibles consecuencias negativas que el dispositivo penal pudiese determinar en el proceso de investigación; por ejemplo, a nivel del vínculo entre el investigador y los/as participantes, y también respecto al proceso de recolección de una información siempre sensible como es la participación en actividades delictivas.

\subsection{Participantes}

De los aproximadamente 40 jóvenes que participaban regularmente en la institución, fue posible tomar contacto con cinco de ellos. Sus edades fluctuaban entre los 15 y 17 años. Estos jóvenes fueron seleccionados en base a: (1) haber participado o participar en actividades infraccionales y (2) su adherencia al programa psicosocial, situación que facilitó el proceso de contacto y vinculación. El resto de los jóvenes del programa no presentaban antecedentes de participación delictiva, o bien no se contó con su interés o las condiciones para su participación.

El presente artículo contemplará principalmente las experiencias de Pablo y Juan, ${ }^{2}$ dos de los cinco jóvenes inicialmente contactados, dado que con los tres jóvenes restantes solo fue posible establecer un vínculo parcial y esporádico. Al momento de realizar el trabajo de campo, Pablo y Juan se hallaban cumpliendo sanciones penales en el marco del sistema LRPA, además de encontrarse desescolarizados, de modo que sus días transcurrían entre la asistencia a los dispositivos penales en los cuales participaban, la realización ocasional de trabajos informales y la convivencia en la calle junto a sus amigos/as.

\subsection{Producción y análisis de la información}

El trabajo de campo consistió en la realización de entre tres y cinco visitas semanales al territorio, entre noviembre del 2015 y febrero del 2016.

\footnotetext{
${ }_{2}$ A fin de velar por el resguardo de la identidad de los participantes de esta investigación, toda la información referida a nombres propios y referencias a lugares han sido debidamente omitidas y/o distorsionadas.
} 
El registro de las observaciones se realizó a través de la confección de notas de campo tras cada visita. Además, se llevaron a cabo ocho entrevistas semiestructuradas con los jóvenes y sus familiares.

El material recogido se analizó desde una perspectiva inductiva analítica (Bernard, 2006), es decir, en virtud de una aproximación "abajo-arriba", obteniendo comprensiones respecto al fenómeno mediante una exploración exhaustiva del material etnográfico. El análisis de los datos se llevó a cabo mediante la confección de un marco descriptivo general a partir de los diarios de campo y las entrevistas realizadas. Posteriormente, a partir de una estrategia abierta y generativa, se realizó un análisis interpretativo en virtud de la identificación de tópicos recurrentes para luego establecer redes capaces de proporcionar comprensiones acerca de las relaciones existentes entre dichos tópicos.

\subsection{Aspectos éticos}

Los jóvenes aceptaron participar informada y voluntariamente en la investigación, tras haber contado previamente con las autorizaciones de sus padres/madres y/o cuidadores/as. La expresión del acuerdo fue respaldada mediante la firma de un asentimiento informado por parte de los jóvenes y de un consentimiento informado por parte de los/las progenitores/as y/o adultas/os responsables.

\section{La vida cotidiana en la calle: aprendizajes, conflictividades y riesgos}

Desde nuestros primeros encuentros, tanto Pablo como Juan destacaron el papel central que "la calle" tenía en su vida cotidiana. Diariamente, los jóvenes recorrían las calles de su barrio tramando intercambios de bienes y favores o urdiendo vínculos de compromiso y amistad. Por lo tanto, la calle era el escenario en el cual los jóvenes entablaban encuentros significativos, por ejemplo, a partir del consumo colectivo de drogas o alcohol, o en virtud de la planificación de algún delito junto a otros jóvenes, a quienes, por dicha razón, calificaban como sus "compañeros". Sin embargo, la calle era además un espacio donde acechaban las más diversas amenazas a la integridad personal. Dentro del barrio eran frecuentes las riñas y los ajustes de cuentas entre jóvenes o bandas rivales, los allanamientos por parte de carabineros, así como también los episodios de violencia desencadenados por una mirada desafiante, o aquellos otros suscitados al fervor de la ingesta de alcohol o drogas. Así, las experiencias de Pablo y Juan parecían sugerir que la calle conjugaba experiencias de alianza y de complicidad con otros, al tiempo que era una especie de escenario incierto en el que amenazaban múltiples peligros. 
Pablo y Juan compartían una misma apreciación acerca de la calle: su carácter eminentemente pedagógico. Tal y como Juan lo dejó en claro: "A mí la calle me ha enseñado hartas cosas. A uno que le gusta la calle, aprende cómo es la calle”. Efectivamente, ambos jóvenes eran sumamente conscientes de las vicisitudes y riesgos que acontecían cotidianamente en la calle. En palabras de Juan: "Puedo caminar por allá y me puede llegar un balazo o me pueden pegar una puñalada o una bala loca ${ }^{[3]}$. Puede chocar la micro ${ }^{[4]}$ ". Es decir, nunca se estaba completamente seguro en la calle, pues los riesgos que allí aparecían la transformaban en una especie de zona opaca, peligrosa y potencialmente mortífera. "Uno no se da ni cuenta cuando va a estar muerto. [...] Un bueón ${ }^{[5]}$ menos, un bueón más, no más. Hay hartos bueones en Santiago para que mueran”, indicó Juan. Por consiguiente, las experiencias de peligro, las posibles alianzas, pero también los conflictos y los dilemas, hacían de la calle tanto un objeto como un escenario que exigía ser aprendido.

Sin embargo, Pablo, Juan y el resto de muchachos del barrio, en modo alguno eran meros agentes reactivos frente a las amenazas que los acechaban en la calle; por ejemplo, una balacera, una redada de carabineros o una pelea con otro joven o una banda rival. Por el contrario, aprender acerca de la vida en la calle implicaba un ejercicio activo respecto de sí mismos y la obligación de actuar adecuadamente en dicho contexto. En palabras de los jóvenes: "saber comportarse", "comportarse bien". Es decir, ejercitar(se) de forma constante en virtud de una serie de normas y códigos de comportamiento propios de la calle, los cuales, en caso de ser transgredidos, aparejaban la posibilidad de sanciones y castigos; por ejemplo, agresiones verbales y/o físicas por parte de otros jóvenes.

Los relatos de Juan nos permiten acceder a una situación dónde justamente asistimos a la puesta en juego de una serie de códigos morales relativos a la regulación y sanción de las relaciones juveniles dentro del barrio. Juan narró un episodio en el cual intentó quitarle la vida a uno de sus excompañeros de delito, pues este lo había traicionado al revelar a los carabineros su participación en un robo conjunto. Detenido y formalizado por el robo a un automóvil, Juan había pasado la noche recluido en el Centro de Justicia de Santiago, mientras que, por el contrario, su compañero no había sido

\footnotetext{
${ }^{3}$ Alude a un proyectil cuyo recorrido no es posible determinar, pudiendo herir o impactar a un inocente.

${ }^{4}$ Autobús de transporte público.

5 Término utilizado para referirse genéricamente a una persona. También alude a aquellas personas que actúan de forma inocente. Dependiendo su uso, puede significar amigo. Por último, se utiliza para referirse a aquellas personas que actúan de forma estúpida.
} 
objeto del mismo tratamiento penal, siendo liberado tras la detención policial. Después de haber sido formalizado y condenado, Juan encontró a su compañero caminando por las inmediaciones de su casa, momento en el cual la situación tomó para él un claro sentido: su compañero lo había delatado, resultando liberado de toda responsabilidad penal. El desenlace no solo fueron los golpes que Juan propinó al presunto delator, sino que lo amenazó de muerte con un revólver.

Empecé a pegarle y casi lo mato [... partí para la casa y saqué una pistola que tenía y casi lo mato. Y mi polola ${ }^{[6]}$ me dijo: “ ¡No, No hagai nada! ¡No hagai maldad! ¿Quieres caer ${ }^{[7]}$ otra vez?”. Y yo le dije: “¡No, pero igual! ¡No me gusta que me sapeen $^{[8]}$ así! ¡No me gusta que sean amarillos ${ }^{[9]}$ ! [...] que sean así que den vuelta la página ${ }^{[10]}$, que anden sapeando".

"Sapear", "ser amarillo" y “que den vuelta la página” fueron las palabras utilizadas por Juan para significar la delación de su ahora excompañero. Palabras que, en su conjunto, habilitan la emergencia de la violencia y la amenaza de la muerte. Sin embargo, lejos de aludir a aquella dimensión caótica y opaca, en virtud de la cual la muerte podía "aparecer en cualquier esquina", o a un presunto "descontrol" referido a los avatares de una individualidad impulsiva, la violencia apareció aquí como una estrategia coherente con los códigos que estructuran los intercambios juveniles, es decir, en conformidad con las normas y valores propios de la economía moral del barrio. En efecto, si hay algo que ponen de manifiesto las palabras de Juan es la fuerza afectiva frente a la ruptura de las complicidades antes establecidas entre ambos jóvenes. Del mismo modo, estas señalan la transgresión de códigos y exigencias vinculadas a los compromisos callejeros, por ejemplo: la rectitud, el silencio y la no delación de un compañero. Así, esta escena nos permite destacar la centralidad que tiene para los jóvenes el sostener las lealtades previamente establecidas; cuestión que no se reduce a una consideración puramente instrumental, sino que enfatiza las normas y los valores que constituyen el compañerismo en condiciones de precariedad (Bourgois y Schonberg, 2009; Fassin, 2018; Karandinos et al., 2014). De acuerdo con lo anterior, esta escena pone de manifiesto cómo la economía moral del barrio implica principios y valores, por ejemplo, de rectitud,

\footnotetext{
${ }^{6}$ Novia.

7 Resultar privado de libertad.

8 Delatar.

9 Desleal, traidor, hipócrita.

10 Hacerse el desentendido. Restar importancia a una situación.
} 
dignidad, justicia y reconocimiento (Fassin, 2018). Valores capaces de performar prácticas y comportamientos que, fuera del contexto particular del barrio, resultarían fácilmente calificados bajo las formas del descontrol, lo ilícito y la transgresión.

\section{3. "Estas son cosas de la calle": interacciones con los dispositivos del sis- tema penal juvenil}

"Oiga, es casi la hora de colación. Usted está citado a las 14:00 [son cerca de las 12:45]. Vamos a ver si la delegada lo puede recibir". Estas fueron las palabras con las cuales Pablo fue recibido por la recepcionista de la institución de cumplimiento de sanciones penales a la cual asistía desde hace casi un año. Al igual que en otras oportunidades, el joven había llegado fuera de horario a entrevista con su delegada, psicóloga supervisora de su sanción y de su reinserción social. Unos minutos después, la delegada hizo su aparición en la sala de recepción. "Yo no debería recibirlo en estas condiciones", señaló, reafirmando la inadecuación del joven y su incapacidad para cumplir la normativa del centro. Manteniendo una postura rígida y seria, la delegada lo increpó nuevamente argumentando que sus constantes inasistencias habían impedido la confección del plan de trabajo a presentar en el tribunal, cuestión que debería ser informada al juez a fin de que este decidiera la aplicación o no de una nueva sanción acorde a los constantes desacatos del joven. $\mathrm{Al}$ respecto, agregó: "veremos qué es lo que decide el juez”. Dos citaciones a entrevista en los próximos cinco días fue el requisito impuesto por la delegada a fin de no envolver al joven, mediante el reporte al tribunal de su falta de adherencia, en un posible quebrantamiento de su sanción por desacato, condición que él aceptó en absoluto silencio. Sin variar su expresión de seriedad y habiendo dado por concluida la entrevista, la delegada entregó una nueva citación a Pablo, ante lo cual este replicó: "Oiga señorita, ¿y quién es este Camilo González?, se equivocó, puso el nombre de otro cabro ${ }^{11}$ ”. Rápidamente, la delegada respondió “ $¡ A y$ ! Me confundí, es el chico que atendí antes que usted. ¡Ve! Eso pasa porque usted no viene, me confundo y se me olvida su nombre".

La trivialidad de esta escena, en modo alguno reduce su importancia. Ello, pues con no menor regularidad Pablo, Juan y otros jóvenes solían criticar a sus delegados/as por las frecuentes recriminaciones que les hacían. Los "tíos" y "tías" -como solían denominarlos-constantemente buscaban corregirlos e increparlos por lo que consideraban como desajustes conductuales: no llegar a la hora, no presentarse a las entrevistas y no colaborar informándoles, por

${ }^{11}$ Muchacho, joven. 
ejemplo, sobre su participación en actividades delictivas y de riesgo. Parecía como si a través de estas reprimendas los/las profesionales buscaran no sólo ajustar a los jóvenes a los marcos normativos exigidos para el cumplimiento de sus sanciones, sino inscribir y reafirmar la ley, por la vía de la coacción, en aquella subjetividad juvenil pretendidamente anómica (Radiszcz et al., 2019). En este sentido, el trato serio y distante que los/las profesionales prodigaban a los jóvenes, su irrestricto apego a las orientaciones administrativas y judiciales, así como sus constantes admoniciones y advertencias parecen operar aquí al modo de estrategias de docilización, de buen encausamiento (Foucault, 2009) y de reconstitución ético-moral (Rose, 2000).

Las experiencias de Pablo y Juan revelan no solo las fricciones y las conflictividades entre los discursos y las estrategias propuestas para los/las jóvenes en el marco de la LRPA, sino también las exigencias de las cuales son objeto en dichos trayectos institucionales. En uno de los últimos encuentros sostenidos con Pablo, este propuso que lo acompañara al programa de Medidas Cautelares en el cual debía presentarse a fin de dar respuesta a un nuevo requerimiento judicial. Días antes, Pablo había sido sorprendido por la policía robando la radio de un automóvil, razón por la cual fue detenido y procesado. La decisión del juez fue que, durante el tiempo que durase la investigación penal, el joven cumpliera una medida cautelar en medio libre. El/la delegado/a tendría aquí la función de acompañarlo, asegurando su participación en cada una de las audiencias judiciales a las que fuera citado hasta el momento en el cual llegara la pena, la cual probablemente sería, dado su historial delictivo, la privación de libertad. Después de su entrevista de ingreso, cuando caminábamos en busca de un refresco, Pablo lanzó sus descargos hacia su nueva delegada. Señaló sentirse molesto porque nuevamente se había visto envuelto en un interrogatorio. Saber si consumía drogas y si aún participaba en delitos, habían sido los focos de la entrevista realizada por la profesional, desdeñando así cualquier otra consideración por su caso.

Le dije que estaba en la casa y que a veces fumaba un pito ${ }^{[12]}$. ¿Qué le iba a decir? Ella me preguntó si fumaba marihuana y si seguía robando. ¡No le iba a decir que fumo todos los días y que todavía sigo robando! [...] Si es para que me ayuden, para no irme en $\operatorname{cana}^{[13]}$ tengo que decirle esas cosas, no que ando robando.

Las palabras de Pablo denuncian la distancia que separa las experiencias juveniles de los discursos, estrategias y prácticas del saber experto. En ellas,

${ }^{12}$ Cigarrillo de marihuana.

${ }^{13}$ Cárcel. 
mediante la admonición y la persuasión, se buscaba la emergencia de una verdad en el joven: que este revele sus crímenes y sus desajustes. La confesión parece ser aquí la condición necesaria para el control, la supervisión y la tutoría del joven. No obstante, tales estrategias no hacen sino invisibilizar al joven y hacerlo desaparecer. No es él quien aparece en su confesión, sino otro, pues para Pablo lo esencial aquí es amargar la posibilidad del encierro. Efectivamente, la amenaza de la privación de libertad es, sin lugar a dudas, una posibilidad siempre presente cuando los jóvenes toman contacto con el sistema penal. No sólo en función de la gravedad de los delitos cometidos, sino también allí donde se quebrantan las normas concernidas en el cumplimiento de una sanción penal en medio libre.

Las relaciones entre los jóvenes y las estrategias psicojurídicas para el control de la delincuencia juvenil no sólo revelan las exigencias y las conflictividades a las cuales estos se ven enfrentados, sino que además manifiestan la distancia y los desencuentros entre los marcos morales desplegados por los agentes del sistema penal y la economía moral encarnada por los jóvenes infractores. Tras una breve conversación con Pablo y sus hermanas, junto a Francisco, educador social del programa psicosocial, decidimos acompañar al joven a la institución en donde cumplía una de sus sanciones. Mientras caminábamos en dirección a la parada de autobuses, Francisco extendió al joven la invitación a una actividad junto a los restantes muchachos del programa psicosocial. Se trataba de una caminata por un parque ubicado en la zona precordillerana de Santiago. Tras escuchar atentamente la propuesta, el joven preguntó: "Oiga tío, ¿y a esa actividad va a ir el Andrés [otro de los jóvenes perteneciente al programa]?”, a lo cual Francisco respondió afirmativamente. Pablo indicó: "mire, yo voy a ir a su actividad y no voy a hacer nada, pero si yo veo a ese loco en la calle yo le voy a pegar". Frente a la mirada de sorpresa del educador, el joven añadió: "Estos son problemas de calle, tío. No tiene que ver con usted o con el paseo. Son atados ${ }^{[14]}$, dramas de la calle, entre nosotros. Si lo veo en la calle [a Andrés] yo le pego, pero obvio que si vamos al paseo no haré nada”.

Mientras Pablo se mantenía serio y en silencio, Francisco, quien estaba al tanto del problema entre ambos jóvenes, pero había restado importancia al hecho, me explicó en qué consistía la situación. El educador me indicó que ambos jóvenes habían tenido una discusión a través de Facebook, porque Andrés se había propasado con una de las amigas de Pablo, hostigándola con obscenidades e insultos. Al enterarse del hecho, Pablo había encarado a Andrés increpándolo por lo que consideraba una falta de respeto hacia

${ }_{14}$ Problemas, conflictos. 
su amiga. "Nos palabreamos ${ }^{[15]}$ por Facebook, se puso pesado ${ }^{[16]}$ con mi amiga... ¿para qué, tío? ¡Eso no se hace! ¡Envarado ${ }^{[17]}$ el loco ${ }^{[18]}$ ! Si lo veo le pego". Ante el silencio del joven, Francisco rápidamente replicó mediante una serie de argumentos relativos a la importancia de afrontar y resolver los problemas "como un adulto", es decir, privilegiando el diálogo en desmedro de la violencia. Tras las palabras del educador, la respuesta del joven no se hizo esperar: “¡Eso no se hace, tío! Por eso yo le voy a pegar. Yo no voy a hacer nada en su actividad, pero yo le voy a pegar. Si quiere invítelo, tío. Yo no haré dramas, son cosas de calle, en la calle se resuelven", señaló de forma enérgica.

¿Qué es lo que realmente importa para el educador y para el joven? Esta escena muestra que, para el educador, el interés central está en la desestimación de la violencia en favor del diálogo, como forma de resolver la querella entre ambos jóvenes. Sin embargo, con ello desestima los valores y exigencias que subyacen en la posición del joven, cuestión que pone de manifiesto la distancia que separa a uno respecto del otro. Para el joven lo que está en juego es la transgresión de Andrés a los códigos y normas que, en la calle, delimitan los asuntos relativos al trato entre hombres y mujeres. Por un lado, el respeto y, sobre todo, la protección de la mujer como un imperativo masculino y, por otro lado, el uso de la violencia como forma legítima de sanción y castigo según los códigos de la calle. De hecho, aun cuando, en sus comentarios tanto Francisco como Pablo parecen enfatizar el respeto y el bienestar del otro, es precisamente la perspectiva universalista del primero (su discurso de la no violencia) la que, paradójicamente, le impide ver lo que esta disputa revela en términos concretos: la vulneración y la falta de respeto hacia una mujer. Por tanto, la apelación del joven a que estas "son cosas de la calle" merece ser entendida, en este contexto, menos como un signo de la existencia de una especie de subcultura callejera y marginal, y más como un reflejo de la distancia y la fricción entre dos marcos morales -distancia de la cual el profesional no es consciente- y también como una reflexión moral profundamente vinculada a la vida cotidiana del barrio (Das, 2006; Kleinman, 1999, 2006) , es decir, a los asuntos que para estos jóvenes importan.

15 Discutir.

${ }^{16}$ Comportarse de forma agresiva.

17 Arrebatado, arrogante. Que falta el respeto a otro.

${ }_{18}$ Término genérico para referirse a una persona. 


\section{4. "Madurar" o cómo convertirse en un hombre y un adulto}

Durante los encuentros sostenidos con los/las educadores/as del programa psicosocial, estos/as profesionales frecuentemente constataron, en una especie de acuerdo tácito, que buena parte de los problemas de estos jóvenes (sus problemas con la ley, en la escuela o en el trabajo) se relacionaban con su incapacidad para madurar, en otras palabras, con el hecho de continuar comportándose como niños cuando debían responder como adultos. Esta consideración deficitarista de lo juvenil responde a una expresión del adultocentrismo en cuanto paradigma de las ciencias sociales en materia de investigación e intervención en torno a lo juvenil en Chile. Imaginario y sistema de dominio que demanda ser leído en clave interseccional, es decir, en articulación con otras categorías tales como género, clase, raza y territorio, entre otras (Duarte Quapper, 2016).

Lo cierto es que, lejos de ser una cuestión puramente local, este discurso relativo a la maduración y el desarrollo juvenil ha sido desde comienzos del siglo xx -al alero de los discursos "psi" y "neuro"- una preocupación coextensiva a muy diversos campos vinculados a la infancia-juventud, sus cuidados, su instrucción y, por cierto, su (re)socialización y su (re)integración social (Béhague y Lézé, 2015; Rose, 1999). De hecho, es precisamente al amparo de la progresiva psicologización y neurobiologización de los asuntos concernientes al derecho penal adolescente, que la maduración y el desarrollo juvenil se encuentra en el centro de las actuales estrategias gubernamentales a nivel nacional para el control de la delincuencia juvenil (Radiszcz et al., 2019). Se trata de la reconstitución ético-moral del adolescente infractor mediante la adquisición de aquellas competencias cognitivas, sociales y morales de las cuales presuntamente carecería a causa de su aún incompleto desarrollo psicológico y cerebral, al tiempo que, de la promoción de valores como la responsabilidad individual, la autonomía, la reflexividad y la capacidad de elección racional (Rose, 1999, 2010).

No obstante, esta apelación a madurar y a "convertirse en un adulto" resultó ser una cuestión que no sólo apareció en el discurso de los/las educadores/as del programa psicosocial, sino que también comprometía personal y colectivamente a los jóvenes, adquiriendo, dentro del contexto cotidiano del barrio, sus propias especificidades y matices. En una de nuestras primeras conversaciones, Juan remarcó que madurar representaba para él: "No tener mente de cabro chico $^{[19]}$, saber comportarse, ir aprendiendo e ir creciendo", en suma "que te vas comportando bien". Efectivamente, madurar fue la palabra con la cual Pablo, Juan y otros jóvenes hicieron referencia a un proceso

${ }_{19}$ Niño, infante. 
amplio -a la vez personal y social, pero también pedagógico y moralizanteen donde diversas dimensiones de la vida juvenil resultaban sobredeterminadas por una suerte de telos moral particular. Según los términos de Pablo: "dejar de ser un cabro chico para ser un hombre y un adulto". Este trayecto desde lo infantil al mundo adulto y masculino sugería la prescripción de todo un conjunto de formas de ser, de pensar, de sentir y de actuar. Tal y como ambos jóvenes lo dejaron en claro, "ser callado", "pensar antes de actuar", "no sentir miedo", "no alardear frente a los otros" y "ser temerario a la hora del robo" eran algunas de las frecuentes exigencias que regulaban el quehacer cotidiano dentro del barrio, determinando distinciones entre los propios jóvenes, así como castigos para quienes las incumplieran. De acuerdo con lo anterior, cabría señalar que desde una perspectiva interseccional (Collins, 2019; Crenshaw, 2017), esta serie de prescripciones representaría estrictos códigos de comportamiento a nivel local relacionados con una modalidad de masculinidad en intersección con una posición de clase urbano popular.

En efecto, buena parte de estas prescripciones aludían a una serie de actitudes y prácticas en donde se intersectaba el género, la clase, lo generacional y lo moral con aquellas dimensiones ligadas al cuerpo y la subjetividad. Pues si lo esencial para estos jóvenes era desligarse de ese momento vital que era la infancia, ello suponía una transformación de sí mismo vinculada a la contención y el autocontrol del cuerpo y los afectos, toda vez que la experiencia propia del cabro chico era la de aquel que se dejaba llevar por sus impulsos. Según los comentarios de ambos jóvenes, "saber comportarse" en la calle y ser competente dentro del campo delictivo suponían la obligatoriedad del autocontrol, cuya condición de posibilidad era el pensamiento. De acuerdo a Juan: "Yo pienso que hay bueones que hacen sin pensar. La mano es pensar y luego hacer". Calcular y pensar significaban aquí un ejercicio constante de regulación en pos del gobierno de sí mismo (Foucault, 2014). En tal sentido, las palabras de ambos jóvenes parecían sugerir que, de lo que se trataba, era de la puesta en juego del pensamiento en favor del autocontrol y de la previsión del futuro. En palabras de Juan:

Antes era Chucky $^{[20]}$ yo, no estaba ni ahí con la gente [...] pero tiempo pasado. Yo no ando hablando ni haciendo problemas [...] Ahora yo pienso como más grande, ¿no? Como diciendo: más mayor. Aprendí a pensar. Antes tenía mentalidad de cabro chico.

${ }^{20}$ Alusión al personaje de la película homónima. Hace referencia a una suerte de "niño problema", agresivo e incontrolable. 
Además, este estricto control de sí se traducía en la proscripción del miedo, la duda y el temor, siendo la audacia y la determinación competencias altamente apreciadas dentro del ámbito callejero y delictivo en los sectores populares. Al respecto, Pablo señaló: "no se trata de cuánto robes, ni de lo que robes, sino de tu actitud". Audacia y determinación a la hora de robar eran, entonces, las aptitudes que permitían a los noveles infractores comenzar a hacerse un nombre dentro del circuito delictivo y callejero. Por el contrario, toda manifestación de duda o temor acarreaba castigos, la pérdida del valor social de sí y, por consiguiente, la exclusión del grupo. Según Pablo:

Si van en el auto y te dicen: “'vamos a pitearnos ${ }^{[21]}$ tal cuestión?", y te tirita la pera ${ }^{[22]}$ ellos te echan para abajo [...] Puede darte la pálida ${ }^{[23]}$, pero que no te tirite la pera [...] Eso le gusta a los hueones, ellos ven eso, no las hueas ${ }^{[24]}$ que robes. Después los machucaos $^{[25]}$ llegaba solitos acá a la casa: "oye, ¿vamos a robar?".

Las palabras de Pablo y Juan parecen sugerir que tanto la reafirmación de la audacia y de la determinación, como la concreción de las exigencias de autocontrol de las manifestaciones físicas y afectivas asociadas al temor permitían a los jóvenes transitar las pruebas y desafíos impuestos a aquellos que buscaban iniciarse en el ámbito callejero y delictivo. Si se analizan los comentarios de Pablo, es posible establecer que el estricto seguimiento de esta especie de "moralidad de los comportamientos" (Foucault, 2009: 25), permitía a los jóvenes obtener el reconocimiento de los delincuentes adultos, quienes oficiaban como agentes de su socialización delictiva ( $\mathrm{Gwadz}$ et al., 2009), transformándose así en miembros de una suerte de comunidad moral y fraterna proscrita para todos aquellos incapaces de ajustarse y sobrellevar las exigencias callejeras y delictivas.

El férreo control que, de manera individual y colectiva, los jóvenes ejercían sobre sí mismos regulaba sus vidas cotidianas e impedía -por ejemplo- acciones que contemplaran dañar y/o matar a otro. Conversando sobre las denominadas monras ${ }^{26}$, Juan señaló que hace aproximadamente un año había ingresado junto a sus compañeros de delito a una vivienda sin percatarse de que en el interior aún se encontraban parte de sus moradores.

\footnotetext{
${ }^{21}$ Romper o estropear. También hace referencia a tomar por asalto un inmueble.

${ }^{22}$ Duda e inseguridad a causa del temor.

${ }^{23}$ Conjunto de sensaciones físicas relacionadas con el miedo y el consumo excesivo de droga. Esta experiencia corporal es comúnmente asociada con aquellos jóvenes sin tolerancia al uso de drogas.

${ }^{24}$ Cosas o artículos en sentido genérico.

${ }^{25}$ Se refiere a aquello que está maltratado o golpeado. También hace referencia a una tercera persona.

${ }^{26}$ Robo en una propiedad destinada a la habitación.
} 
Específicamente, Juan habló de la presencia de una abuela, a quien maniataron y amenazaron a fin de poder sustraer, sin la menor resistencia, artículos electrónicos, dinero y joyas. Sin embargo, tras lo que denominó como "la bajada de la adrenalina", aquello que capturó su mirada fue el rostro asustado de la mujer y su posterior desmayo. En su vulnerabilidad y terror, el rostro y el cuerpo desvanecido de la anciana hicieron emerger en Juan las figuras de su propia abuela, de su madre y de su bisabuela, reactualizando con ello su propia posición infantil en tanto hijo y nieto. Al respecto, indicó: "A uno no le gustaría que le pasara lo mismo a la familia de uno", tras lo cual reafirmó el corolario que desde aquella oportunidad dirigiría sus inserciones delictivas: "que nunca se te pase la mano ${ }^{[27]}$ con otro".

$\mathrm{Al}$ respecto, diversas perspectivas dentro de las ciencias sociales han enfatizado en la proliferación de tendencias anómicas y violentas al interior de los barrios empobrecidos y marginalizados, ya sea a partir de su presunta desorganización social (Shaw y McKay, 1942) o bien en virtud de su empobrecimiento organizacional a causa de factores estructurales (Wacquant, 2004). Igualmente, diversas investigaciones provenientes de los saberes "psi" y "neuro" han destacado la presunta inclinación connatural de los adolescentes al riesgo, la agresividad y la transgresión, dado su aún incompleto desarrollo psicológico y neurobiológico (Iselin et al., 2009; Pardini y Loeber, 2008). Sin embargo, precisamente la escena antes descrita permite cuestionar este carácter anómico y deficitario comúnmente atribuido tanto a las condiciones sociales de los barrios empobrecidos como a los propios jóvenes (Caldeira, 2009). La experiencia de Juan pone de manifiesto el férreo control que los jóvenes ejercen sobre sí mismos bajo la forma del autocontrol y la inhibición de la agresión a otros. Al mismo tiempo, denota las limitaciones y regulaciones que la economía moral (sus normas, sus códigos y sus expectativas) impone sobre los montos y las modalidades de expresión de la violencia interpersonal (Rodgers, 2006, 2015). En tal sentido, lejos de ser un fenómeno caótico y desregulado, la experiencia juvenil del barrio sugiere que la violencia toma formas e intensidades específicas según códigos y normas locales, exigencias que enfrentan a los jóvenes a dilemas y conflictos morales.

\section{Conclusiones}

La vida cotidiana del barrio en el cual Pablo, Juan y otros jóvenes se desenvolvían se perfilaba como un complejo circuito en donde la ley, la transgresión y la moral se imbricaban en modos paradojales. Robos, riñas callejeras

${ }^{27}$ Excederse. 
y conflictos entre bandas rivales eran algunas de las formas en virtud de las cuales los jóvenes habitaban su barrio. No obstante, lejos de reflejar un presunto desgobierno a nivel personal o una supuesta proliferación de tendencias anómicas, tales prácticas parecen concernir a un conjunto de exigencias morales y prescripciones normativas situadas.

La experiencia cotidiana de los jóvenes permite destacar cómo la vida del barrio se estructura al modo de un particular campo de fuerzas en donde las prácticas y actividades juveniles encarnan obligatorias formas de ser, actuar y sentir. Es decir, aquellas prácticas juveniles que en principio podrían ser calificadas apresuradamente bajo la rúbrica de lo mórbido, lo ilícito y lo transgresivo emergen ahora situadas en un particular entramado moral atravesado por una serie de valores, normas y expectativas locales. Desde esta perspectiva, la economía moral del barrio y la experiencia moral juvenil parecen ser centrales a la hora de comprender el modo en que estos habitan lo social, su inserción en prácticas delictivas y el modo en que se vinculan con los dispositivos y estrategias dispuestas por la LRPA.

Desde una perspectiva ingenua y, por cierto, no muy alejada de algunas ideas alojadas en el sentido común respecto a la "delincuencia juvenil", podríamos pensar que los jóvenes que han cometido actos delictivos carecen de las competencias cognitivas y morales -o que no han alcanzado la madurez-para conducirse adecuadamente en sociedad o, incluso, que dicha disfunción social se encontraría determinada por componentes psicopatológicos. Sin embargo, lejos de los ya reconocidos reduccionismos deficitaristas y psicopatologizantes, en virtud de los cuales han sido ampliamente estudiadas las prácticas delictivas y de riesgo juveniles en Chile desde el campo "psi-neuro" (véase, por ejemplo, Fundación Tierra Esperanza, 2012; Gaete et al., 2014; MINSAL, 2007; Rioseco et al., 2009), las experiencias de los jóvenes del barrio parecen reflejar la adecuación de la subjetividad y el cuerpo juvenil a una serie de normas y códigos morales tendientes justamente al gobierno y regulación de los impulsos. "Dejar de ser un niño" en busca de una cierta interpretación de lo adulto y lo masculino emerge en la vida social del barrio a modo de un principio teleológico, capaz de estructurar formas específicas de actuar, pensar, sentir y relacionarse.

A partir de lo anterior, podemos dar cuenta de los conflictos, fricciones y desencuentro entre las experiencias juveniles y los principios y estrategias jurídico-penales, psicoeducativas y sanitarias enmarcadas en el nuevo modelo de responsabilidad penal juvenil. Dichas interacciones vendrían de la mano de una dificultad a la hora de reconocer una cierta forma de vida (Das, 1998). En efecto, la vida cotidiana y las prácticas juveniles parecen revelar la existencia de una particular economía moral marginalizada. Se trata, 
tal y como hemos descrito, de la producción, circulación y utilización de un conjunto de valores, normas, obligaciones y emociones morales ligadas a lo masculino y lo adulto, las cuales constituirían una gramática moral situada acorde a las particularidades de la vida en los barrios marginalizados. Así, los conflictos, fricciones y desencuentros entre la experiencia juvenil y las estrategias que componen el modelo de responsabilidad penal adolescente toman sentido a partir del desconocimiento activo de dicha dimensión local de la vida social y moral juvenil. A este respecto, las estrategias jurídico-penales y los discursos "psi-neuro" involucrados sucumbirían a la tentación de interpretar las prácticas juveniles como una mera desviación de las normas sociales, buscando entonces que los jóvenes se ajusten e interioricen la ley, desconociendo con ello las particulares lógicas y dinámicas del campo social que habitan y construyen cotidianamente.

El material etnográfico nos permite poner de manifiesto las fricciones entre una forma de vida juvenil relacionada con agencias, prácticas y modalidades específicas de responsabilidad moral y los discursos hegemónicos penales y de salud mental relativos a la juventud en conflicto con la ley. Consideramos que es necesario el desarrollo de investigaciones de corte cualitativo y etnográfico a nivel nacional, que permitan acceder a las relaciones entre las instituciones disciplinarias y sanitarias, la vida cotidiana y la subjetividad de los jóvenes en conflicto con la ley, relevando aspectos de género, clase, raza/etnia y generacionales involucrados. En tal sentido, nos parece central la propuesta de Fassin (2016), para quien el proceso etnográfico supone la construcción de una proximidad, en aras de una reducción de la otredad. Ello pues, aquellos jóvenes en situación de conflictividad con la ley resultan precisamente reducidos a una alteridad peligrosa y extranjera.

Revisado por José Morales

\section{Referencias bibliográficas}

BCN - Biblioteca del Congreso Nacional de Chile (s.f.), "Peñalolén - Reporte Comunal I 2015”. Consultado el 10.09.2019, en https://www.bcn.cl/siit/reportescomunales/ reporpdf.html?anno=2015\&idcom $=13122$.

Béhague, Dominique (2009), "The Dilemmas of Politically Sensitive Medicalized Approaches to Reducing Youth Violence in Pelotas, Brazil", in Gareth A. Jones; Dennis Rodgers (comps.), Youth Violence in Latin America. Gangs and Juvenile Justice in Perspective. New York: Palgrave MacMillan, 133-149.

Béhague, Dominique; Lézé, Samuel (2015), "Shaping the Modern Child: Genealogies and Ethnographies of Developmental Science”, Social Science \& Medicine, 143, 249-254. 
Bernard, Harvey Russel (2006), Research Methods in Antbropology: Qualitative and

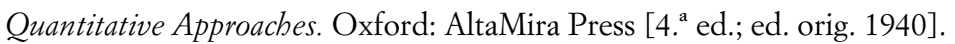

Bourgois, Philippe; Schonberg, Jeff (2009), Righteous Dopefiend. Berkeley: University of California Press.

Caldeira, Teresa (2009), "Marginality, Again?!", International Journal of Urban and Regional Research, 33(3), 848-853.

Carreño Hernández, Mauricio (2016), "Excesos de ley. Aproximaciones a la experiencia moral de un grupo de jóvenes en conflicto con la ley”. Tesis de Maestría en Psicología Clínica de Adultos, Departamento de Psicología, Facultad de Ciencias Sociales, Universidad de Chile, Santiago de Chile, Chile.

Collins, Patricia Hill (2019), Intersectionality as Critical Social Theory. Durham: Duke University Press.

Crenshaw, Kimberlé (2017), On Intersectionality. Essential Writings. New York: The New Press.

Das, Veena (1998), “Wittgenstein and Anthropology”, Annual Review of Antbropology, 27, 171-195.

Das, Veena (2006), Life and Words: Violence and the Descent into the Ordinary. California: California University Press.

Das, Veena (2012), “Ordinary Ethics”, in Didier Fassin (comp.), A Companion to Moral Anthropology. New York: John Wiley \& Sons, 133-149.

Duarte Quapper, Klaudio (2016), “Genealogía del adultocentrismo. La construcción de un patriarcado adultocéntrico”, in Klaudio Duarte Quapper; Carolina Álvarez Valdés (eds.), Juventudes en Chile. Miradas de jóvenes que investigan. Santiago: Social-Ediciones, 17-47.

Fassin, Didier (2016), La fuerza del orden. Una etnografía del accionar policial en las periferias urbanas. Buenos Aires: Siglo XXI. Traducción de Andrea Sosa Varrotti.

Fassin, Didier (2018), Por una repolitización del mundo. Las vidas descartables como desafíos del siglo XXI. Buenos Aires: Siglo XXI. Traducción de Horacio Pons.

Foucault, Michel (2009), Vigilar y castigar. Nacimiento de la prisión. Buenos Aires: Siglo XXI. Traducción de Aurelio Garzón del Camino [2. ${ }^{a}$ ed.; ed. orig. 1975].

Foucault, Michel (2014), Del gobierno de los vivos. Curso en el Collège de France (1979-1980). Buenos Aires: Fondo de Cultura Económica. Traducción de Horacio Pons.

Fundación Tierra Esperanza (2012), "Estudio diagnóstico de la situación actual de la atención en salud mental y psiquiatría para la población de adolescentes que cumplen condena en CIP-CRC”. Santiago: Fundación Tierra Esperanza.

Gaete, Jorge; Labbé, Nicolás; Villar, Paloma del; Allende, Catalina; Valenzuela, Eduardo (2014), "Prevalencia de trastornos psiquiátricos en adolescentes infractores de ley en Chile”, Revista Médica de Chile, 142(11), 1377-1384. 
García, Angela (2014), “The Promise: On the Morality of Marginal and the Illicit”, Ethos, 42(1), 51-64.

Gwadz, Marya Viorst; Gostnell, Karla; Smolenski, Carol; Willis, Brian; Nish, David; Nolan, Theresa C.; Tharaken, Maya; Ritchie, Amanda S. (2009), "The Initiation of Homeless Youth into the Street Economy”, Journal of Adolescence, 32(2), 357-377.

Iselin, Anne-Marie; DeCoster, Jamie; Salekin, Randall (2009), "Maturity in Adolescent and Young Adult Offenders: The Role of Cognitive Control", Law and Human Behavior, 33(6), 455-469.

Karandinos, George; Hart, Laurie Kain; Montero Castrillo, Fernando; Bourgois, Philippe (2014), “The Moral Economy of Violence in the US Inner City”, Current Anthropology, 55(1), 1-22.

Kleinman, Arthur (1999), "Moral Experience and Ethical Reflection: Can Ethnography Reconcile Them? A Quandary for 'the New Bioethics'”, Daedalus, 128(4), 69-97. Consultado el 15.09.2019, en http://www.jstor.org/stable/20027589.

Kleinman, Arthur (2006), What Really Matters: Living a Moral Life Amidst Uncertainty and Danger. New York: Oxford University Press.

Knoblauch, Hubert (2005), "Focused Ethnography", Forum Qualitative Sozialforschun/ Forum: Qualitative Social Research, 6(3), art. 44. Consultado el 10.09.2019, en http:// www.qualitative-research.net/index.php/fqs/article/view/20/43.

Lambek, Michael (2010), "Toward an Ethics of the Act”, in Michael Lambek (comp.), Ordinary Ethics: Anthropology, Language and Action. New York: Fordham University Press, 1-39.

MINSAL - Ministerio de Salud (2007), “Atención de niños, niñas y adolescentes con trastornos mentales usuarios del Servicio Nacional de Menores”. Santiago de Chile: Ministerio de Salud. Consultado el 10.09.2019, en https://www.minsal.cl/portal/url/ item/71e518399a8cbccae04001011f013167.pdf.

Pardini, Dustin A.; Loeber, Rolf (2008), "Interpersonal Callousness Trajectories across Adolescence: Early Social Influences and Adult Outcomes", Criminal Justice and Behavior, 35(2), 173-196.

Radiszcz, Esteban; Carreño Hernández, Mauricio; Abarca Brown, Gabriel; Abarzúa, Marianella (2019), "¿Sujetos de derecho o sujetos al desarrollo? Crimen y castigo juvenil en la justicia penal chilena”, Dilemas, 12(2), 309-332. Consultado el 10.09.2019, en https://revistas.ufrj.br/index.php/dilemas/article/view/17629.

Rioseco, Pedro; Vicente, Benjamin; Saldivia, Sandra; Cova, Félix; Melipillán, Roberto; Rubi, Patricia (2009), "Prevalencia de trastornos psiquiátricos en adolescentes infractores de ley. Estudio caso-control”, Revista Chilena de Neuropsiquiatría, 47(3), 190-200.

Rodgers, Dennis (2006), "Living in the Shadow of Death: Gangs, Violence and Social Order in Urban Nicaragua, 1996-2002”, Journal of Latin American Studies, 38(2), 267-292. 
Rodgers, Dennis (2015), “The Moral Economy of Murder: Violence, Death, and Social Order in Nicaragua", in Javier Auyero; Philippe Bourgois; Nancy Scheper-Hughes (comps.), Violence at the Urban Margins. New York: Oxford University Press, 21-40.

Rose, Nikolas (1999), Governing the Soul: The Shaping of the Private Self. London: Routledge.

Rose, Nikolas (2000), "Government and Control”, The British Journal of Criminology, 40(2), 321-339.

Rose, Nikolas (2012), Políticas de la vida: biomedicina, poder y subjetividad en el siglo XXI. La Plata: UNIPE. Traducción de Elena Luján Odriozola.

Rose, Nikolas; Abi-Rached, Joelle M. (2013), Neuro. The New Brain Science and the Management of the Mind. Princeton: Princeton University Press.

Shaw, Clifford R.; McKay, Henry D. (1942), Juvenile Delinquency and Urban Areas. Chicago: University of Chicago Press.

Tsukame, Alejandro (2017), Jóvenes desacreditados. Ideologías y estrategias de control de la delincuencia juvenil en el neoliberalismo chileno (1990-2015). Santiago de Chile: Ediciones Universidad Academia de Humanismo Cristiano.

Vidal, Fernando; Ortega, Francisco (2017), Being Brains: Making the Cerebral Subject. Oxford: Oxford University Press.

Wacquant, Loïc (2004), "Decivilizing and Demonizing: The Remaking of the Black America Ghetto”, in Steven Loyal; Stephen Quilley (comps.), The Sociology of Norbert Elias. Cambridge: Cambridge University Press, 95-121.

\section{Mauricio Carreño Hernández}

Doctorante en el Departamento de Antropología, Filosofía y Trabajo Social, Universitat Rovira i Virgili I LaPSoS - Laboratorio Transdisciplinar en Prácticas Sociales y Subjetividad, Universidad de Chile Av. Catalunya, n. ${ }^{\circ}$ 35, Tarragona, CP: 43002, España Contacto: mauricioalexis.carreno@estudiants.urv.cat ORCID: https://orcid.org/0000-0001-9534-6220

\section{Gabriel Abarca-Brown}

Facultad de Psicología, Universidad Diego Portales | LaPSoS - Laboratorio Transdisciplinar en Prácticas Sociales y Subjetividad, Universidad de Chile Vergara, n. ${ }^{\circ}$ 275, Santiago, Región Metropolitana, CP: 8320000, Chile Contacto: gabrielabarcabrown@gmail.com ORCID: https://orcid.org/0000-0001-5369-1616 


\section{Esteban Radiszcz}

Departamento de Psicología, Universidad de Chile I LaPSoS - Laboratorio Transdisciplinar en Prácticas Sociales y Subjetividad, Universidad de Chile

Av. Capitán Ignacio Carrera Pinto, n. ${ }^{\circ}$ 1045, Nuñoa, Región Metropolitana, CP: 7750000, Chile

Contacto: eradiszcz@uchile.cl

ORCID: https://orcid.org/0000-0002-3282-6670

Recibido: 10.07.2020

Aceptación comunicada: 16.11.2021

https://doi.org/10.4000/rccs.12420

\section{Everyday Life and Moral Experiences of a Group of Young People in Conflict with the Law in Santiago, Chile}

We explore the everyday life of a group of young people in conflict with the law and the relationships they maintain with the devices and strategies of the Law 20.084 on Adolescent Criminal Responsibility (LRPA). First, we describe the ethnographic context of the research. Then, we show their forms of sociability, moral experiences and interactions between young people and the adolescent penal system's devices. Materials suggest that young people's experiences are closely linked to a series of local values, norms and expectations around representations about masculinity and adulthood. Thus, through their moral experiences, young people reveal how they engage with criminal practices, as well as identifying their points of friction and conflict with the LRPA strategies.

Keywords: Chile; everyday life; juvenile delinquency; penal responsibility.

\section{Vie quotidienne et expériences morales d'un groupe de jeunes en conflit avec la loi à Santiago, Chili}

Dans cet article nous explorons la vie quotidienne d'un groupe de jeunes en conflit avec la loi et leurs relations avec les dispositifs et les stratégies de l'actuelle Loi 20.084 sur la responsabilité pénale des adolescents (LRPA). À ce titre, nous décrivons le contexte ethnographique de la recherche. Par la suite, nous montrons les modes de sociabilité des jeunes, leurs expériences morales et les interactions qu'ils maintiennent avec les dispositifs de la LRPA. Les matériels suggèrent que l'expérience de la jeunesse est liée aux valeurs, codes, normes et attentes locales articulées aux représentations du masculin et de l'adulte. Ainsi, les jeunes révèlent, à travers leurs expériences morales, les façons dont ils s'engagent dans des pratiques délictuelles, de même que les frictions et les conflits qu'ils maintiennent avec les dispositifs et les stratégies de LRPA.

Mots-clés: Chili; délinquance juvénile; responsabilité pénale; vie quotidienne. 
